\title{
The tip of the iceberg: Evaluating the mechanism behind dehiscence of mitral annuloplasty rings
}

\author{
John W. MacArthur, MD, and Jack Boyd, MD
}

\footnotetext{
From the Department of Cardiothoracic Surgery, Falk Cardiovascular Research Center, Stanford University School of Medicine, Stanford, Calif.

Disclosures: Authors have nothing to disclose with regard to commercial support.

Received for publication Aug 27, 2017; accepted for publication Aug 30, 2017; available ahead of print Sept 22, 2017.

Address for reprints: Jack Boyd, MD, Department of Cardiothoracic Surgery, Falk Cardiovascular Research Center, Stanford University, 300 Pasteur Dr, Stanford, CA 94305 (E-mail: jackboyd@ stanford.edu).

J Thorac Cardiovasc Surg 2018;155:140-1

$0022-5223 / \$ 36.00$

Copyright $(2) 2017$ by The American Association for Thoracic Surgery

http://dx.doi.org/10.1016/j.jtcvs.2017.08.099
}

Over the past few decades, the rapid advancement of imaging technology has resulted in better understanding of the dynamic changes that take place along the mitral annulus during the cardiac cycle. This information has been leveraged in the treatment of mitral valve regurgitation, specifically when it comes to the concept and design of annuloplasty rings, an integral component of surgical mitral valve repair. Although annuloplasty rings are generally durable over time, ring dehiscence from the annulus is a wellrecognized cause for failure of mitral valve repair. Several large, retrospective reports indicate that when mitral valve repairs fail, $13 \%$ to $42 \%$ of the time this failure is due to ring dehiscence. ${ }^{1,2}$ As such, it is important to explore the mechanism behind annuloplasty ring dehiscence to further reduce the failure rate of mitral valve repair.

In the current issue, Pierce and colleagues ${ }^{3}$ explore the variable forces to which annuloplasty rings and their anchoring sutures are subject over the cardiac cycle using an ovine model. This study builds on previous publications $^{4,5}$ by authors who have pioneered the study of mitral valve biomechanics. In previous work, ${ }^{4,5}$ the development of suture force transducers applied to an implantable annuloplasty ring demonstrated that force distribution along the mitral annulus is not uniform and is variable throughout the cardiac cycle. Additionally, it appears that collagen content (there is reduced collagen density in this region) is directly related to the force necessary to tear out an anchoring annuloplasty stitch, shedding light on why dehiscence along the posterior annulus is more common.,

In the study by Pierce and colleagues, ${ }^{3} 23$ sheep were implanted with either Physio (Edwards, Irvine, Calif) or Profile 3D (Medtronic, Sunnyvale, Calif) annuloplasty rings all custom engineered with suture force transducers. Groups were further divided into true-sized annuloplasty rings or undersized annuloplasty rings (by 2 sizes). Data were acquired on beating hearts with standardized left ventricular pressures starting at $100 \mathrm{~mm} \mathrm{Hg}$, increasing to $125 \mathrm{~mm} \mathrm{Hg}$, and finally at $150 \mathrm{~mm} \mathrm{Hg}$. The force with which each suture was tied down (securing the ring to the annulus) and the

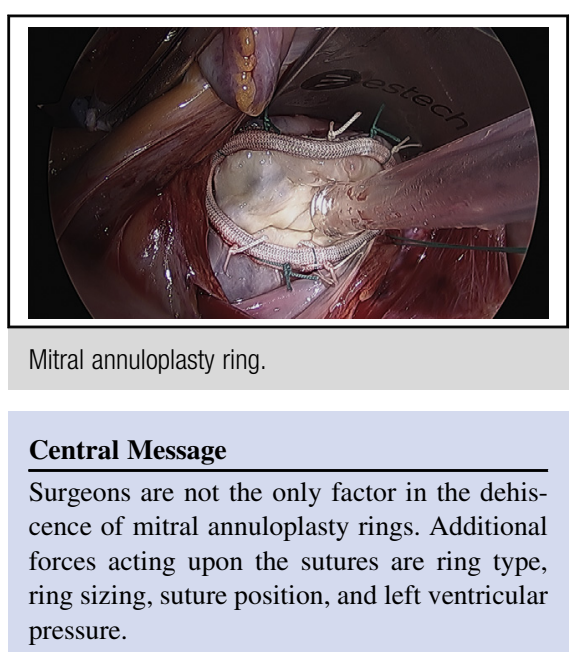

See Article page 131

contractile force (the force experienced by the sutures and therefore the ring during the cardiac cycle) were acquired at the above-mentioned afterload conditions. In the study, the force used by the surgeon tying the suture and securing the annuloplasty ring was independent from the force those sutures experience during the cardiac cycle. If we extrapolate these data, we can assume that a suture that is only loosely secured will not decrease the final force applied to that suture during myocardial contraction. This is not necessarily intuitive, but it supports what surgeons learn during their training in knot-tying mechanics: approximate and do not strangulate.

Another interesting finding of this study was the relationship between contractile forces on the sutures and ring type. Use of a true-sized ring reduced contractile forces, which is logical because it is physiologic and does not constrain the annulus. They draw the interesting conclusions that a truesized ring only experiences reduced contractile force along the anterior annulus and that a posterior annulus experiences the same force whether using a true-sized ring or an undersized ring. Due to the fact that the collagen density of the anterior annulus is greater than the posterior annulus, and therefore can tolerate much higher tensile force, this would predispose to dehiscence along the posterior annuluswhich is what is seen clinically. Finally, when looking at the differences between the Physio and Profile 3D groups, the only difference that reached statistical significance was that true-sized Physio rings reduced contractile force, whereas undersizing with the Profile 3D led to more uniform 
contractile force across all anchoring sutures. Due to the multivariable nature of the rings used (ie, rigidity and shape), the causality of these differences is difficult to assess.

We have gained a mechanistic understanding of why there is a propensity for annuloplasty rings to dehisce along the posterior annulus: perhaps not due to surgical error, but rather more closely related to annuloplasty design and variable force dynamics throughout the cardiac cycle. Although there remains much work to be done on the optimal technique and device design for mitral valve repair, this article ${ }^{3}$ continues to move us toward the knowledge we need to make this a reality and we look forward to reading other results from this group in the future.

\section{References}

1. Gillinov AM, Cosgrove DM, Lytle BW, Taylor PC, Stewart RW, McCarthy PM et al. Reoperation for failure of mitral valve repair. J Thorac Cardiovasc Surg. 1997; 113:467-75

2. Dumont E, Gillinov AM, Blackstone EH, Sabik JF III, Svensson LG, Mihaljevic T, et al. Reoperation after mitral valve repair for degenerative disease. Ann Thorac Surg. 2007;84:444-50

3. Pierce EL, Bloodworth CH IV, Siefert AW, Easley TF, Takayama T, Kawamura T, et al. Mitral annuloplasty ring suture forces: impact of surgeon, ring, and use conditions. J Thorac Cardiovasc Surg. 2018;155: 131-9.e3.

4. Siefert AW, Pierce AL, Lee M, Jensen MO, Aoki C, Takebayashi S, et al. Suture forces in undersized mitral annuloplasty: novel device and measurements. Ann Thorac Surg. 2014;98:305-9.

5. Pierce EL, Siefert AW, Paul DM, Wells SK, Bloodworth CH, Takebayashi S, et al How local annular force an collagen density govern mitral annuloplasty ring dehiscence risk. Ann Thorac Surg. 2016;102:518-26. 